\title{
Vorwort zur zweiten Auflage
}

Die zweite Auflage meines Lehrbuches übergebe ich der Öffentlichkeit mit einigen Verbesserungen und Ergänzungen. Von wesentlichen Ånderungen in der Anordnung des Lehrstoffes habe ich Abstand genommen, weil viele Zuschriften der Anerkennung von hervorragenden Fachleuten bekundeten, daß ich das Richtige getroffen habe.

Anregungen $\mathrm{zu}$ Verbesserungen auch in der vorliegenden zweiten Auflage würde ich dankbar begrüßen.

Aachen, im April I92I.

H. Repenning.

\section{Vorwort zur dritten Auflage}

Die dritte Auflage meines Lehrbuches ist in der bewährten Form geblieben und nur im Anhang ergänzt worden. Dadurch ist eine kurze Wiederholung des Lehrstoffes und eine Übersicht über dic wesentlichsten Fortschritte im Webstuhlbau gegeben.

Aachen, im März I926.

H. Repenning.

\section{Vorwort zur vierten Auflage}

Auch die vierte Auflage meines Lehrbuches ist in der alten Form geblieben. Durch Ergänzungen in gedrängter Form habe ich eine kleine Erweiterung hinzugefügt. Es lag der Versuch nahe, alle bisher erschienenen Patente oder Neuerungen zu besprechen. Bei näherer Prüfung bin ich aber hiervon abgekommen, da die Grundlagen im vorliegenden Lehrbuch schon enthalten sind.

Aachen, im August I94I.

H. Repenning. 